\title{
Consequences of violating the assumption of independence in the process dissociation procedure: A word fragment completion study
}

\author{
RICCARDO RUSSO and ANNE M. CULUIS \\ University of Essex, Colchester, England \\ and \\ ALAN J. PARKIN \\ University of Sussex, Brighton, England
}

\begin{abstract}
In three experiments that used levels of processing and study time manipulations as independent variables in a word fragment completion task, the validity of the assumption of independence between recollection and automatic influences of memory was assessed. This assumption underlies the use of the process dissociation procedure (Jacoby, 1991), a tool suggested for distinguishing the different contributions of recollection and automatic influences of memory. Overall, it appeared that semantic processing, as compared with physical processing at study, positively affected recollection but negatively affected automatic influences of memory in word fragment completion. This negative effect on the automatic influences was reduced when the available study time decreased. The incompatibility of these results with the assumption of independence between recollection and automatic influences of memory and their impact on the applicability of the process dissociation procedure are discussed.
\end{abstract}

In the last decade, there has been a growing interest in the distinction between implicit/indirect and explicit/ direct memory tasks. Several independent variables, such as generating versus reading targets (see, e.g., Blaxton, 1989), divided versus focused attention at study (see, e.g., Mulligan \& Hartman, 1996; Parkin, Reid, \& Russo, 1990), and intentional versus incidental learning (see, e.g., Neill, Beck, Bottalico, \& Molloy, 1990), have been shown to distinguish between these tasks. These results have provided a basis for theorizing about different processes or systems underlying implicit and explicit memory (for reviews, see Roediger \& McDermott, 1993; Schacter, Chiu, $\&$ Ochesner, 1993).

One of the limitations in contrasting performances in direct and indirect tasks concerns the possible use of explicit memory strategies to perform an indirect task. This may cause problems in assessing the effect of a variable on implicit/automatic memory processes. It has been shown,

\footnotetext{
Portions of this article were presented in April 1996 at the annual conference of the British Psychological Society. The present study was supported by a grant from The Nuffield Foundation to R.R. We thank Tim Curran, Douglas Hintzman, Elliot Hirshman, Thomas Nelson, Alan Richardson-Klavehn, David Shanks, and an anonymous reviewer for their helpful comments on earlier drafts of this paper. R.R. thanks the members of the Memory Club of the Department of Psychology of the University of Essex for useful discussions about the theoretical issues raised in the paper and Vani Kouloheri for support. Correspondence concerning this article should be addressed to R. Russo, Department of Psychology, University of Essex, Wivenhoe Park, Colchester CO4 3SQ, England (e-mail: rrusso@essex.ac.uk).
}

-Accepted by previous editor, Geoffrey R. Loftus for example, that aging affected performance in a picture fragment completion task, when the influence of explicit recollection was not controlled for. Consequently, age effects disappeared when explicit recollection was partialed out from the indirect performance (Russo \& Parkin, 1993).

To overcome the above problem, Jacoby (1991) proposed a process dissociation procedure (PDP) for assessing the contribution of recollection and automatic influences (the terms components and retrieval modes will be used alternatively) of memory. In the case of memory tasks based on cue completion, this is accomplished by combining the results of an inclusion and an exclusion version of a completion task. In the inclusion version (i.e., a modified cued-recall task), subjects are required first to complete a test cue with a study word, and, if this fails, they are required to complete the cue with the first word that comes to mind. Therefore, the probability of responding with a studied word in the inclusion version of a cue completion task is given by the probability of explicitly recollecting a target item $[R]$ plus the probability of the word being brought to mind automatically $[\mathrm{A}]$ when recollection fails $[A *(1-R)]$.

In the exclusion test, subjects are required to complete a test cue with a word not presented at study. Here, explicit recollection is acting in opposition to cue completion, and the probability of completing a cue with a studied word is given by the probability of the word being brought to mind automatically when recollection fails $[A *(1-R)]$.

To summarize, the probabilities of completing a cue with a target word in the inclusion and exclusion versions of a cue completion task are, respectively, 
Inclusion:

$$
R+A *(1-R) \text { or, equivalently, } R+A-A * R
$$

and

Exclusion:

$$
A *(1-R) \text { or, equivalently, } A-A * R .
$$

Subtracting the probability of target completion in the exclusion task from the probability of target completion in the inclusion test provides an estimate of the recollection influences of memory. The automatic influences of memory are estimated by the ratio Exclusion/( $1-R)$ - that is, $A *(1-R) /(1-R)$. This last equation reflects both the automatic influences of memory and baseline completion probability. Assuming that these two effects are additive, it is necessary to subtract the baseline performance from $A$, in order to gain a purer estimate of the automatic influences of memory.

One of the assumptions underlying the use of the PDP is that subjects use the same criterion when responding to test cues in both inclusion and exclusion conditions. A test for this relies on the comparison between the baseline guessing rates in the inclusion and exclusion tasks. A further critical assumption underlying the PDP is that the probability of completing a cue under automatic retrieval is stochastically independent of the probability of completing the same cue under the recollection influences of memory.

Jacoby and his collaborators (e.g., Jacoby, Toth, \& Yonelinas, 1993; Toth, Reingold, \& Jacoby, 1994) intended to provide support for this last assumption by showing that, in line with data from direct and indirect memory tasks (see, e.g., Graf \& Mandler, 1984; Parkin et al., 1990), variables such as divided attention and levels of processing selectively affected the recollection but not the automatic influences of memory. However, it is important to note that independence is assumed by the PDP; therefore, accumulating instances of lack of dependence do not necessarily support independence, whereas dependence would strongly suggest that this underlying assumption might not be warranted. In fact, two recently published studies employing the PDP in word completion tasks showed results that are at variance with the assumption of independence between recollection and automatic influences of memory (Curran \& Hintzman, 1995; Russo \& Andrade, 1995). The first study used a word stem completion task, and the critical manipulation was the different amounts of time allowed for learning to commit target items to memory. In the second study, a word fragment completion task was used, and the critical manipulation at study was instructing the subjects, on an item-by-item basis, to remember or to forget targets (i.e., directed forgetting manipulation). On the basis of the positive effect that such variables exert on direct memory tasks and their lack of effect on indirect memory tasks (see, e.g., B.H. Basden, D.R. Basden, \& Gargano, 1993; Neill et al., 1990), these variables should be expected to affect recollection memory components but not to influence automatic memory components. In fact, they exerted a positive influence on the recollection influences of memory but had a reverse effect on automatic memory. A viable psychological interpretation of these reverse effects seems difficult, unless, contrary to all empirical evidence from the implicit memory literature, it is accepted that reducing study time and asking subjects to forget rather than to remember target items increases the probability of automatically retrieving targets. Instead, the same reverse effects were suggested to be a by-product of the lack of independence between the recollection and the automatic influences of memory.

A proposal to explain such spurious reverse effects as those previously described has been recently put forward by Curran and Hintzman $(1995,1997)$. They proposed that such reverse effects can be explained if recollection and automatic components are positively correlated across items within each subject. In Figure 1 (upper part), two hypothetical bivariate distributions of correlated values of $\mathrm{R}$ and $\mathrm{A}$ are presented. The shape of each distribution is elliptical, to indicate that $\mathrm{R}$ and $\mathrm{A}$ are positively correlated. The ellipse on the left may represent the $R$ and $A$ distribution for to-be-forgotten items, whereas the ellipse displaced to the right along the $\mathrm{R}$ axis may represent the same distribution for to-be-remembered items. This displacement indicates that instructions to remember positively affect recollection. There is no displacement of the two distributions on the ordinate, indicating that, as expected from the results of studies using indirect tests of memory, no effect of directed forgetting is expected on the automatic influences of memory. Given that the automatic influences of memory are estimated when recollection fails, and given that recollection fails more often for to-be-forgotten than for to-be-remembered items (i.e., observations to the left of the criterion line are not recollected), it appears that $A$ is estimated on reduced samples of items in both the to-be-forgotten and the tobe-remembered conditions. As a consequence of this selection bias, the values of $\mathrm{A}$ for to-be-forgotten and tobe-remembered conditions that are calculated using the PDP will underestimate the automatic influence of memory for both the experimental conditions. Moreover, since the item selection bias is more pronounced for the distribution of the items that are remembered more often-that is, to-be-remembered items - an artifactual dissociation is obtained: The estimate of the automatic influences of memory for the to-be-forgotten items is larger than that obtained for the to-be-remembered items. Figure 1 (bottom part) shows the same two uncorrelated distributions of $R$ and $A$ values as prescribed by the independent assumption. In this case, no relationship occurs between $R$ and $A$; thus, the item selection bias does not affect the estimates of the automatic influences of memory in the two distributions. Under the independent relationship between 


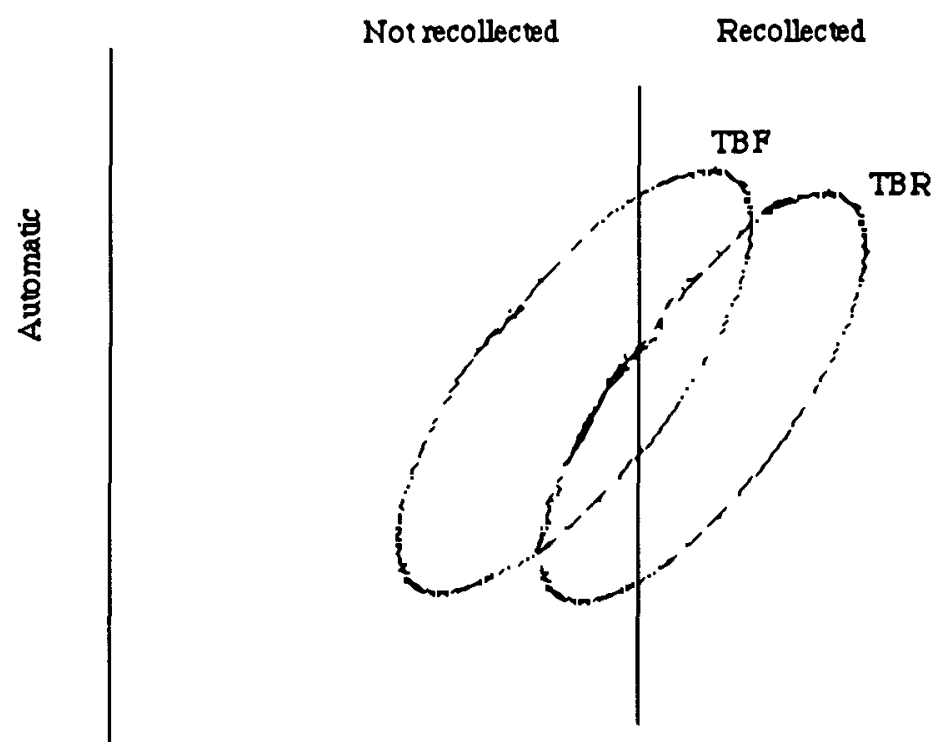

Recollection

Not recollected Recollected

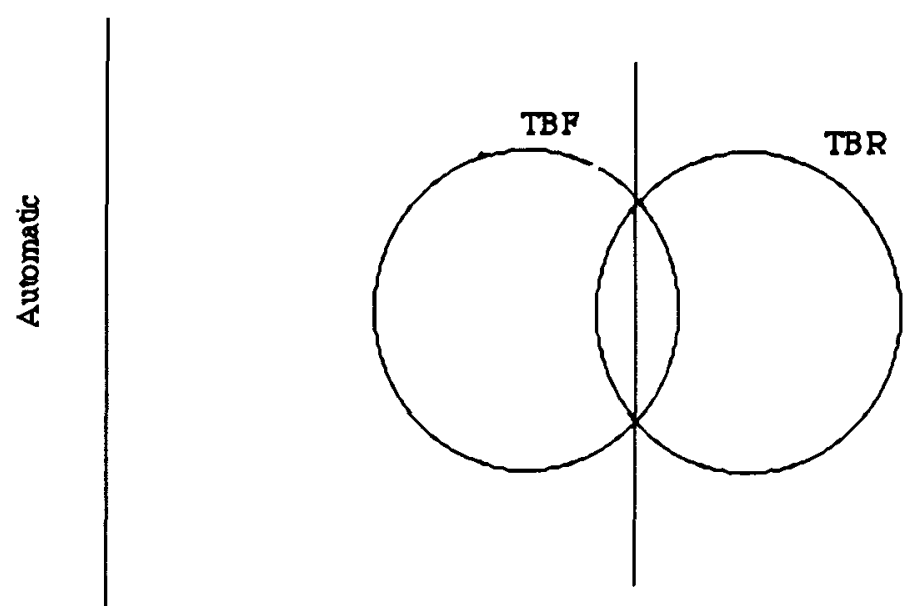

Recollection

Figure 1. Hypothetical representation of recollection (on the abscissa) and automatic (on the ordinate) influences of memory on each observation (i.e., item) in each subject when these components are positively related (upper part) and when these components are independent (lower part). The vertical line in the middle of the pictures indicates the criterion for recollection. Items to the left of the criterion are not recollected. Estimates of the automatic influences of memory are based on the subset of items to the left of the criterion. TBF, to be forgotten items; TBR, to be remembered items.

the $\mathrm{R}$ and $\mathrm{A}$ components, no effect of directed forgetting should then be detected on the estimated automatic influences of memory obtained with the PDP.

The aim of the present study is to show that, using the PDP, it is possible to obtain spurious dissociations between recollection and automatic influences of memory, other than those previously described, which indicate a violation of the independence assumption. This is done by manipulating levels of processing (LOP) of target material as the independent variable in a word fragment completion task modified according to PDP. Three experiments are presented, and they differ only in the amount of time allowed for carrying out the orienting task at study. Deep/semantic processing has been shown to induce better performance than does shallow/physical processing in direct memory tasks, while, in general, leaving 
unaffected performance in indirect memory tasks (see, e.g., Graf \& Mandler, 1984; Hamman \& Squire, 1996; but see Brown \& Mitchell, 1994). As a consequence, it is expected that LOP should exert its effect on the recollection influences of memory, while leaving unaffected the automatic influences of memory. A reverse effect of physical over semantic processing on the automatic components, if found, would not be predicted on theoretical grounds, and this would indicate that recollection and automatic components are related, thus violating the assumption of independence between these memory components. It is relevant to note that Toth et al. (1994) showed, using a word stem completion task modified according to the PDP, that the estimates of the recollection components were larger after semantic than after physical processing of targets, but that there was no LOP effect on the automatic components. Notice also, as previously stated, that this result does not necessarily support a relation of independence between memory components. A reverse LOP effect, being a positive finding, would strongly suggest that this underlying assumption may not be warranted.

A secondary aim of this study is to contrast different predictions that can be made about the estimates that could be obtained with the PDP if recollection and automatic retrieval are either independent or positively related. Given a positive relationship between the recollection and the automatic influences of memory, the larger the positive influence of a variable on recollection, the larger the underestimation of automatic retrieval (see Figure 1). If there is a relation of independence between recollection and automatic retrieval, instead, no underestimation of automatic retrieval should be observed. A parametric manipulation of study time, a variable expected to affect the recollection but not the automatic influences of memory (see, e.g., Neill et al., 1990) was used to test the above predictions. An analysis comparing the results obtained in the three reported experiments will be employed to address this issue.

\section{EXPERIMENT 1}

\section{Method}

Subjects. Forty-eight subjects from the students and staff members of the University of Essex took part in Experiment 1.

Materials and Design. One-hundred and fifty-six English words, ranging in length from 5 to 12 letters, and their corresponding fragments, were taken from the samples of words used by Blaxton (1989) and by Srinivas and Roediger (1990). These words were divided into six subsets comprising 26 words each $\left(\mathrm{A}_{1}, \mathrm{~B}_{1}, \mathrm{C}_{1}, \mathrm{~A}_{2}\right.$, $\left.B_{2}, C_{2}\right)$, and subsequently combined into three sets $(A, B, C)$, each comprising 52 words, where each set was formed joining the subsets with a common letter (see the Appendix for the full list of words and fragments employed).

A study list comprised two sets of words presented in different blocks. The remaining set was used as the baseline condition at test. Two orienting tasks, aimed to induce semantic and physical analysis of targets, were used for the incidental learning of target words that is, rating pleasantness and counting ascending and descending letters. Each subject undertook the two orienting tasks (S, P). To counterbalance the sets with the orienting tasks, six study lists were created (i.e., AB, BA, BC, CB, CA, AC), and two orders were used for the orienting tasks (i.e., SP, PS).

Two test lists $\left(T_{1}, T_{2}\right)$ were formed. These comprised the fragments corresponding to the subsets $A_{1}, B_{1}, C_{1}, A_{2}, B_{2}$, and $C_{2}$ and 56 fragments from different words that were used as fillers in order to ensure an equal number of new and old words at test. In the test list $T_{1}$, fragments corresponding to subsets $A_{1}, B_{1}$, and $C_{1}$ and to 26 filler words were assigned to the inclusion test condition, whereas the fragment corresponding to subsets $A_{2}, B_{2}$, and $C_{2}$ and to the remaining 26 filler words were assigned to the exclusion test condition. In the test list $T_{2}$, the test conditions were reversed. In each test list, the fragments from the various subsets and the inclusion/ exclusion instruction assignments were randomly allocated, with the proviso that no more than three contiguous items could be taken from the same subset. The complete counterbalancing required 24 subjects. Target and baseline fragments mainly had unique completions. In a few cases, more than one solution was possible.

Procedure. The subjects were tested individually. Stimuli were presented in lower case on a computer screen. In order to promote incidental study of the target words, subjects were told that they were taking part in a normative study involving several different tasks.

In the semantic study condition, the subjects were asked to rate the pleasantness of each word using a 5-point scale ( 5 indicating very pleasant, and 1 very unpleasant). In the physical condition, they were asked to count the number of ascending and descending letters present in each word; these are the letters that extend above or below the main body of the word. Before each set of words was presented, the subjects were given the appropriate orienting task instructions. Each word was presented for $1.5 \mathrm{sec}$, with a 0.5 -sec blank interval in between. The study session lasted about $5 \mathrm{~min}$.

The test followed immediately after learning took place. At test, each fragment appeared on the screen for $8 \mathrm{sec}$. The list of fragments was also provided on paper so that the subjects could write the response on the sheet. To the left of each word, either the letter $O$ or the letter $\mathrm{N}$ was printed. These letters indicated that a specific fragment had to be treated according to the inclusion $(\mathrm{O})$ or the exclusion $(\mathrm{N})$ instruction. A beep marked the end presentation of a test fragment and indicated to the subjects that they should move to the next item. An interval of $0.5 \mathrm{sec}$ occurred between the end of the presentation of a fragment and the presentation of the one following. The first 10 fragments at test were taken from filler words, so as to provide subjects with the opportunity to practice the task.

In the inclusion condition, the subjects were asked first to complete each fragment with a word seen at study. If they could not remember the appropriate word, the subjects were asked to produce another word that could fit the fragment. The subjects were told that it was acceptable to leave blank any fragment that they could not complete. In the exclusion condition, the subjects were asked to complete fragments with words not presented at study or to leave blank any fragment that they could not complete.

To summarize, a factorial design was used with study (semantic vs. physical processing) and test (inclusion vs. exclusion) as withinsubjects factors.

\section{Results}

A potential problem that may arise in applying the PDP equations is that, if no fragments are completed in the exclusion condition, the estimated automatic component is set to zero. This leads to the underestimation of the automatic component. In order to overcome this problem, two methods have been used. The first method requires that the estimates of $R$ and $A$ for each subject be calculated and that those subjects who scored zero in the exclusion task be removed from the analyses. Inferential analyses on both the full sample and the reduced sample (i.e., no 
Table 1

Experiment 1: Percentage of Correctly Completed Fragments (With Standard Errors) as a Function of Study and Test Conditions

\begin{tabular}{|c|c|c|c|c|c|c|}
\hline \multirow[b]{3}{*}{ Test } & \multicolumn{6}{|c|}{ Study } \\
\hline & \multicolumn{2}{|c|}{ Semantic } & \multicolumn{2}{|c|}{ Physical } & \multicolumn{2}{|c|}{ Baseline } \\
\hline & $M$ & $\overline{S E}$ & $M$ & $\overline{S E}$ & $M$ & $S E$ \\
\hline Inclusion & 0.51 & 0.02 & 0.39 & 0.02 & 0.28 & 0.02 \\
\hline Exclusion & 0.11 & 0.01 & 0.30 & 0.02 & 0.26 & 0.02 \\
\hline
\end{tabular}

zero exclusion) are presented. The second method, suggested by Curran and Hintzman (1995), is to estimate R and $\mathrm{A}$, pooling all the observations across items and subjects. Inferential analyses to compare pairs of estimates were carried out using the $Z$ test (the standard error of the difference between proportions was employed). ${ }^{1}$

Subject analysis. For each subject, the percentage of the completed fragments in the inclusion and the exclusion conditions for both semantically and physically processed words was calculated. The percentage of the completed fragments for the new items served as a measure of baseline performance (Table 1). A 2 (inclusion vs. exclusion) $\times 2$ (semantic vs. physical) within-subjects analysis of variance (ANOVA) was performed on these data. There was a significant effect of test type $[F(1,47)=174.71$, $\left.M S_{\mathrm{e}}=0.016, p<.01\right]$, indicating that more fragments were completed in the inclusion than in the exclusion test condition. The effect of the orienting task was significant $\left[F(1,47)=9.32, M S_{\mathrm{e}}=0.006, p<.01\right]$, indicating that more fragments were completed in the physical condition. More important, the interaction was significant $[F(1,47)=$ $\left.170.32, M S_{\mathrm{e}}=0.007, p<.01\right]$, indicating that semantic and physical processing had different effects in the inclusion and exclusion conditions. Simple main effects indicated an advantage of the semantic processing condition at inclusion $\left[F(1,47)=56.69, M S_{\mathrm{e}}=0.006, p<.01\right]$, whereas more fragments were completed in the physical processing condition at exclusion [i.e., a reverse LOP effect; $\left.F(1,47)=129.73, M S_{\mathrm{e}}=0.007, p<.01\right]$.

Baseline performance did not differ between inclusion and exclusion test conditions $\left[F(1,47)=1.25, M S_{\mathrm{e}}=0.01\right.$, $p>.10]$.

The estimates of the recollection and automatic influences of memory calculated with the previously presented formulas are presented in Table 2. A 2 (recollection vs. automatic) $\times 2$ (semantic vs. physical) within-subjects ANOVA was performed on these data for the full sample of subjects. Estimates of the recollection influences of memory were not significantly larger than estimates of the automatic influences of memory $[F(1,47)<1]$. The effect of the orienting task manipulation was significant $\left[F(1,47)=37.98, M S_{\mathrm{e}}=0.005, p<.01\right]$, indicating larger estimates under semantic than under physical processing. The interaction was significant $\left[F(1,47)=169.26, M S_{\mathrm{e}}=\right.$ $0.014, p<.01]$, indicating the differential effect of semantic and physical processing on the estimates of the recollection and automatic influences of memory. Simple main effects showed that there was an advantage of the semantic over the physical processing condition at recollection $\left[F(1,47)=169.27, M S_{\mathrm{e}}=0.012, p<.01\right]$, whereas a reverse advantage emerged for the automatic component $\left[F(1,47)=80.32, M S_{\mathrm{e}}=0.008, p<.01\right]$.

In order to assess the presence of above chance performance at the level of the automatic influences of memory, two paired $t$ tests were performed on the mean completed fragments at baseline versus the estimates of the automatic influences of memory, for both the semantic and the physical processing conditions. These analyses indicated that automatic estimates in the physical condition were significantly above chance $[t(47)=4.50, p<.01]$, whereas in the semantic condition, automatic estimates were significantly below chance $[t(47)=-5.26, p<.01]$. Overall, these data suggest the presence of some degree of dependency between the recollection and the automatic influences of memory. ${ }^{2}$

Only 1 subject did not complete any fragment in the semantic exclusion conditions. The data when this subject was removed are presented in Table 2. The removal of this subject from the analysis of the estimates of the recollection and automatic components did not change the results of the analyses presented above. There was an advantage after semantic processing at recollection $\left[F(1,46)=162.67, M S_{\mathrm{e}}=\right.$ $0.012, p<.01]$ and an advantage of physical processing in the estimates of the automatic influences of memory $\left[F(1,46)=76.14, M S_{\mathrm{e}}=0.008, p<.01\right]$. Automatic estimates in the physical condition were significantly above chance $[t(46)=4.62, p<.01]$, whereas, in the semantic condition, automatic estimates were significantly lower than chance $[t(46)=-5.09, p<.01]$.

Table 2

Experiment 1: Estimates of Recollection and Automatic Influences of Memory (With Standard Errors) in the Semantic and Physical Conditions

\begin{tabular}{|c|c|c|c|c|c|c|c|}
\hline \multirow[b]{3}{*}{ Sample } & \multirow[b]{3}{*}{ Test } & \multicolumn{6}{|c|}{ Study } \\
\hline & & \multicolumn{2}{|c|}{ Semantic } & \multicolumn{2}{|c|}{ Physical } & \multicolumn{2}{|c|}{ Baseline } \\
\hline & & $\mathrm{E}$ & $S E$ & $E$ & $S E$ & $\mathrm{E}$ & $S E$ \\
\hline \multirow[t]{2}{*}{ Full } & Recollection & 0.40 & 0.02 & 0.11 & 0.02 & & \\
\hline & Automatic & 0.18 & 0.02 & 0.34 & 0.02 & 0.27 & 0.01 \\
\hline \multirow[t]{2}{*}{ Reduced (47 subjects) } & Recollection & 0.40 & 0.02 & 0.11 & 0.02 & & \\
\hline & Automatic & 0.18 & 0.02 & 0.34 & 0.02 & 0.27 & 0.01 \\
\hline
\end{tabular}

Note-The upper part presents the estimates obtained from the full sample. The lower part presents the estimates obtained from the reduced sample (i.e., no zero at exclusion). 
Table 3

Experiment 2: Percentage of Correctly Completed Fragments (With Standard Errors) as a Function of Study and Test Conditions

\begin{tabular}{|c|c|c|c|c|c|c|}
\hline \multirow[b]{3}{*}{ Test } & \multicolumn{6}{|c|}{ Study } \\
\hline & \multicolumn{2}{|c|}{ Semantic } & \multicolumn{2}{|c|}{ Physical } & \multicolumn{2}{|c|}{ Baseline } \\
\hline & $M$ & $S E$ & $M$ & $S E$ & $M$ & $S E$ \\
\hline Inclusion & 0.56 & 0.02 & 0.47 & 0.03 & 0.33 & 0.02 \\
\hline Exclusion & 0.24 & 0.03 & 0.40 & 0.02 & 0.32 & 0.02 \\
\hline
\end{tabular}

Analyses on pooled data. The PDP formulas were applied to the pooled means obtained in the inclusion, exclusion, and baseline conditions, collapsing the data across all subjects and items, in order to estimate recollection and automatic influences of memory. The analysis on the pooled data was comparable with that on the subject analyses. There was a significant difference between the semantic and the physical processing on the estimates of the recollection influences of memory $\left(R_{\text {semantic }}-R_{\text {physical }}=\right.$ $0.31 ; Z=19.28, S E=0.016$ ) and a reverse effect on the estimates of the automatic influences of memory $\left(A_{\text {semantic }}\right.$ $\left.-\mathrm{A}_{\text {physical }}=-0.14 ; Z=-8.31, S E=0.017\right)$. Automatic estimates were significantly larger than baseline for the physical processing condition ( $A_{\text {physical }}$ - baseline $=0.06$; $Z=3.45, S E=0.018$ ) and significantly smaller than baseline for the semantic processing condition $\left(\mathrm{A}_{\text {semantic }}-\right.$ baseline $=-0.08 ; Z=-4.85, S E=0.017)$.

\section{Discussion}

The utilization of the PDP showed an advantage of semantic over physical incidental study at recollection, whereas an advantage of physical over semantic processing occurred in the case of automatic retrieval. Estimates of automatic influences of memory were significantly above chance in the physical condition, whereas, in the semantic condition, these were significantly smaller than baseline. These results were not predicted on theoretical grounds, but they are a plausible consequence of a violation of the assumption of independence between recollection and the automatic components. Since "complete independence of bases for judgements ( 0 covariance)" (Jacoby, 1991, p. 530) is assumed by the PDP, we believe that the present results, coupled with the results obtained by Curran and Hintzman (1995) and by Russo and Andrade (1995), make the use of this procedure doubtful, at least when applied to modified cued-completion memory tasks.

The present results contrast with those obtained by Toth et al. (1994, Experiment 1) by manipulating LOPs in a word stem completion task. In this study, LOP was found to affect the recollection but not the automatic influences of memory. Since the advantage of physical over semantic processing at automatic retrieval in our study may reflect a Type I error, we decided to try to replicate the results obtained in the present experiment. The following two experiments were intended to replicate Experiment 1 , in which the only difference was in the time allowed for performing the orienting tasks at study. This was reduced from 1.5 to $1.3 \mathrm{sec}$ in Experiment 2 and to $1.0 \mathrm{sec}$ in Experiment 3. The manipulation of study time was intended, as was mentioned in the introduction, to test different predictions that can be made about the estimates obtainable by the PDP, when recollection and automatic retrieval are either independent or positively related. The rationale underlying this test will be clarified after the presentation of Experiments 2 and 3, when an analysis comparing the three experiments will be given.

\section{EXPERIMENT 2}

\section{Method}

Subjects. Forty-eight subjects from the students and staff members of the University of Essex took part in Experiment 2. None of these subjects took part in the previous experiment.

Materials, Design, and Procedure. The same design, materials, and procedure as those used in Experiment 1 were employed in the present experiment. The only change was the presentation time at study. The subjects had $1.3 \mathrm{sec}$ to perform the required orienting tasks on each word at study.

\section{Results}

Subject analysis. As in the previous experiment, the percentage of the completed fragments in the inclusion and the exclusion conditions was calculated for each subject, for both semantically and physically processed words. The percentage of the completed fragments for the new items served as a measure of baseline performance (Table 3). A 2 (inclusion vs. exclusion) $\times 2$ (semantic vs. physical) within-subjects ANOVA was performed on these data. More fragments were completed in the inclusion than in the exclusion test condition $[F(1,47)=60.34$, $\left.M S_{\mathrm{e}}=0.03, p<.01\right]$. The effect of the orienting task was marginally significant $\left[F(1,47)=3.67, M S_{\mathrm{e}}=0.012, p=\right.$ $.062]$, indicating that more fragments were completed in the physical condition. The interaction was significant $\left[F(1,47)=38.32, M S_{\mathrm{e}}=0.019, p<.01\right]$, indicating that semantic and physical processing had different effects in the inclusion and exclusion conditions. Simple main effects indicated an advantage of the semantic processing condition at inclusion $\left[F(1,47)=13.54, M S_{\mathrm{e}}=0.016\right.$, $p<.01]$, whereas more fragments were completed after the physical processing at exclusion $[F(1,47)=36.15$, $\left.M S_{\mathrm{e}}=0.016, p<.01\right]$

Baseline performance did not differ between inclusion and exclusion test conditions $(F<1)$.

The PDP estimates of the recollection and automatic influences of memory are presented in Table 4. A 2 (recollection vs. automatic) $\times 2$ (semantic vs. physical) within-subjects ANOVA was performed on these data for the full sample of subjects. Automatic estimates were significantly larger than recollection estimates $[F(1,47)=$ $\left.24.14, M S_{\mathrm{e}}=0.058, p<.01\right]$. The estimates obtained under the semantic condition were larger than those obtained under the physical condition $\left[F(1,47)=8.29, M S_{\mathrm{e}}=\right.$ $0.015, p<.01]$. The interaction was significant $[F(1,47)=$ $\left.41.82, M S_{\mathrm{e}}=0.034, p<.01\right]$, indicating the differential 
Table 4

\begin{tabular}{|c|c|c|c|c|c|c|c|}
\hline \multicolumn{8}{|c|}{$\begin{array}{l}\text { Table 4 } \\
\text { Experiment 2: Estimates of Recollection and } \\
\text { Automatic Influences of Memory (With Standard Errors) } \\
\text { in the Semantic and Physical Conditions }\end{array}$} \\
\hline \multirow[b]{3}{*}{ Sample } & \multirow[b]{3}{*}{ Test } & \multicolumn{6}{|c|}{ Study } \\
\hline & & \multicolumn{2}{|c|}{ Semantic } & \multicolumn{2}{|c|}{ Physical } & \multicolumn{2}{|c|}{ Baseline } \\
\hline & & $\mathrm{E}$ & $S E$ & $\mathrm{E}$ & $S E$ & $\mathrm{E}$ & $S E$ \\
\hline Full & $\begin{array}{l}\text { Recollection } \\
\text { Automatic }\end{array}$ & $\begin{array}{l}0.33 \\
0.33\end{array}$ & $\begin{array}{l}0.03 \\
0.03\end{array}$ & $\begin{array}{l}0.10 \\
0.45\end{array}$ & $\begin{array}{l}0.02 \\
0.02\end{array}$ & 0.33 & 0.02 \\
\hline Reduced (43 subjects) & $\begin{array}{l}\text { Recollection } \\
\text { Automatic }\end{array}$ & $\begin{array}{l}0.31 \\
0.36\end{array}$ & $\begin{array}{l}0.04 \\
0.03\end{array}$ & $\begin{array}{l}0.09 \\
0.45\end{array}$ & $\begin{array}{l}0.02 \\
0.02\end{array}$ & 0.33 & 0.02 \\
\hline
\end{tabular}

Note-The upper part presents the estimates obtained from the full sample. The lower part presents the estimates obtained from the reduced sample (i.e., no zero at exclusion).

effect of semantic and physical processing on the estimates of the recollection and automatic influences of memory. Simple main effects showed that there was an advantage of the semantic over the physical processing condition at recollection $\left[F(1,47)=36.52, M S_{\mathrm{e}}=0.033, p<.01\right]$, whereas a reverse advantage emerged for the automatic component $\left[F(1,47)=21.40, M S_{\mathrm{e}}=0.016, p<.01\right]$.

In order to assess the presence of above chance performance at automatic retrieval, two paired $t$ tests were performed on the mean completed fragments at baseline versus the estimates of the automatic influences of memory for both the semantic and the physical processing conditions. These analyses indicated that automatic estimates in the physical condition were significantly above chance $[t(47)=8.05, p<.01]$, whereas, in the semantic condition, automatic estimates were not different from chance $[t(47)=-.07, p>.10]$. As in the previous experiment, these data suggest the presence of some dependency between recollection and the automatic influences of memory.

Five subjects did not complete any fragment in the semantic exclusion condition. The data when these subjects are removed are presented in Table 4. The removal of these subjects from the analysis of the estimates of the recollection and automatic components did not affect the pattern of the results obtained in the analyses conducted on the full sample. There was an advantage after semantic processing at recollection $\left[F(1,42)=28.07, M S_{\mathrm{e}}=0.034\right.$, $p<.01]$ and an advantage after physical processing in the estimates of the automatic influences of memory $\left[F(1,42)=14.81, M S_{\mathrm{e}}=0.012, p<.01\right]$. Automatic estimates in the physical condition were significantly above chance $[t(42)=7.97, p<.01]$, whereas, in the semantic condition, automatic estimates were not significantly different from chance $[t(42)=1.44, p>.10]$.

Analyses on pooled data. The PDP formulas were applied to the pooled means obtained in the inclusion, exclusion, and baseline conditions, collapsing the data across all subjects and items. The analyses of the pooled data were comparable to that obtained on the subject analyses. There was a significant difference between the semantic and the physical processing on the estimates of the recollection influences of memory $\left(R_{\text {semantic }}-R_{\text {physical }}=\right.$
$0.25 ; Z=16.56, S E=0.015)$ and a reverse effect on the automatic estimates $\left(A_{\text {semantic }}-A_{\text {physical }}=-0.07 ; Z=\right.$ $-3.66, S E=0.019$ ). Automatic estimates were significantly larger than baseline for the physical processing condition $\left(\mathrm{A}_{\text {physical }}\right.$ - baseline $\left.=0.10 ; Z=5.13, S E=0.019\right)$ and not significantly different from baseline for the semantic processing condition $\left(\mathrm{A}_{\text {semantic }}-\right.$ baseline $=0.03$; $Z=1.47, S E=0.019$ ).

\section{Discussion}

Experiment 2 replicated most of the results obtained in Experiment 1. There was an advantage of semantic over physical processing at recollection, whereas an advantage of physical over semantic processing occurred in the case of the automatic retrieval. Estimates of the automatic influences of memory were significantly above chance in the physical condition, whereas, in the semantic condition, these were now not significantly different from baseline. As in the case of the previous experiment, these data suggest the presence of some degree of dependency between recollection and automatic influences of memory. It also appears that the removal of those subjects scoring zero at exclusion after semantic processing increased the estimates of automatic retrieval for this processing condition. Overall, study time reduction from 1.5 to $1.3 \mathrm{sec}$ seems to have reduced both the advantage of semantic over physical processing at recollection and the advantage of physical over semantic processing at automatic retrieval.

As previously stated, Experiment 3 is a further attempt to replicate Experiment 1 results with a study time of $1.0 \mathrm{sec}$.

\section{EXPERIMENT 3}

\section{Method}

Subjects. Forty-eight subjects from the students and staff members of the University of Essex took part in Experiment 3. None of these subjects took part in the previous experiments.

Materials, Design, and Procedure. The same design, materials, and procedure as those used in the previous two experiments were employed. The only change was the presentation time at study, which was further reduced. Subjects had $1.0 \mathrm{sec}$ to perform the required orienting tasks on each word at study. 
Table 5

Experiment 3: Percentage of Correctly Completed Fragments (With Standard Errors) as a Function of Study and Test Conditions

\begin{tabular}{|c|c|c|c|c|c|c|}
\hline \multirow[b]{3}{*}{ Test } & \multicolumn{6}{|c|}{ Study } \\
\hline & \multicolumn{2}{|c|}{ Semantic } & \multicolumn{2}{|c|}{ Physical } & \multicolumn{2}{|c|}{ Baseline } \\
\hline & $M$ & $S E$ & $M$ & $S E$ & $M$ & $S E$ \\
\hline Inclusion & 0.51 & 0.03 & 0.44 & 0.03 & 0.33 & 0.02 \\
\hline Exclusion & 0.25 & 0.03 & 0.37 & 0.02 & 0.32 & 0.02 \\
\hline
\end{tabular}

\section{Results}

Subject analysis. The percentage of the completed fragments in the inclusion and the exclusion conditions was calculated for each subject for both semantically and physically processed words and for new words (Table 5) A 2 (inclusion vs. exclusion) $\times 2$ (semantic vs. physical) within-subjects ANOVA on these data showed that more fragments were completed in the inclusion than in the exclusion test condition $\left[F(1,47)=30.89, M S_{\mathrm{e}}=0.042, p<\right.$ $.01]$. The effect of the orienting task was not significant $\left[F(1,47)=2.31, M S_{\mathrm{e}}=0.013, p>.10\right]$. The interaction was significant $\left[F(1,47)=26.49, M S_{\mathrm{e}}=0.019, p<.01\right]$, indicating that semantic and physical processing had different effects in the inclusion and exclusion conditions. Simple main effects indicated an advantage of the semantic processing condition at inclusion $[F(1,47)=9.91$, $\left.M S_{\mathrm{e}}=0.010, p<.01\right]$, whereas more fragments were completed in the physical processing condition at exclusion $\left[F(1,47)=18.35, M S_{\mathrm{e}}=0.017, p<.01\right]$.

Baseline performance did not differ between inclusion and exclusion test conditions $(F<1)$.

The PDP estimates of the recollection and automatic influences of memory are presented in Table 6. A 2 (recollection vs. automatic) $\times 2$ (semantic vs. physical) withinsubjects ANOVA was performed on these data for the full sample of subjects. Automatic estimates were significantly larger than recollection estimates $[F(1,47)=15.28$, $\left.M S_{\mathrm{e}}=0.083, p<.01\right]$. The main effect of processing conditions missed conventional levels of significance $\left[F(1,47)=3.48, M S_{\mathrm{e}}=0.007, p<.07\right]$. The interaction was significant $\left[F(1,47)=27.07, M S_{\mathrm{e}}=0.034, p<.01\right]$, indicating the differential effect of semantic and physical processing on the estimates of the recollection and automatic influences of memory. Simple main effects showed that there was an advantage of the semantic over the physical processing condition at recollection $[F(1,47)=$ $\left.34.34, M S_{\mathrm{e}}=0.015, p<.01\right]$, whereas a reverse advantage emerged for the automatic influences of memory $\left[F(1,47)=12.85, M S_{\mathrm{e}}=0.020, p<.01\right]$.

Automatic estimates in the physical condition were significantly larger than baseline $[t(47)=5.47, p<.01]$, whereas, in the semantic condition, automatic estimates were not different from chance $[t(47)=-.33, p>.10]$. As for the previous experiment, these data suggest the presence of some dependency between the recollection and the automatic influences of memory.

Six subjects did not complete any fragment in the semantic exclusion condition. The data when these subjects were removed are presented in the lower part of Table 6 . No substantial differences emerged from the analyses carried out on the full sample. There was an advantage after semantic processing at recollection $[F(1,41)=$ $\left.23.80, M S_{\mathrm{e}}=0.016, p<.01\right]$ and an advantage of physical processing in the estimates of the automatic influences of memory $\left[F(1,41)=5.21, M S_{\mathrm{e}}=0.016, p<.03\right]$. Automatic estimates in the physical condition were significantly larger than baseline $[t(41)=5.09, p<.01]$, whereas, in the semantic condition, automatic estimates were not significantly different from chance $[t(41)=0.96, p>.10]$.

Analyses on pooled data. The PDP formulas were applied to the pooled means obtained in the inclusion, exclusion, and baseline conditions, collapsing the data across all subjects and items. The analyses on the pooled data were comparable to those obtained on the subject analyses. There was a significant difference between the semantic and the physical processing on the estimates of recollection $\left(\mathrm{R}_{\text {semantic }}-\mathrm{R}_{\text {physical }}=0.18 ; Z=12.62, S E=0.014\right)$ and a reversal of this effect on the automatic estimates $\left(\mathrm{A}_{\text {semantic }}-\mathrm{A}_{\text {physical }}=-0.06 ; Z=-3.02, S E=0.019\right)$. Automatic estimates were significantly larger than baseline for the physical processing condition $\left(\mathrm{A}_{\text {physical }}-\right.$ baseline $=0.08 ; Z=3.94, S E=0.019)$ and not significantly different from baseline for the semantic processing condition $\left(\mathrm{A}_{\text {semantic }}-\right.$ baseline $\left.=0.02 ; Z=0.92, S E=0.019\right)$.

\section{Discussion}

Experiment 3 replicated most of the results obtained in the previous two experiments. There was an advantage of semantic over physical processing at recollection,

Table 6

Experiment 3: Estimates of Recollection and Automatic Influences of Memory (With Standard Errors) in the Semantic and Physical Conditions

\begin{tabular}{|c|c|c|c|c|c|c|c|}
\hline \multirow[b]{3}{*}{ Sample } & \multirow[b]{3}{*}{ Test } & \multicolumn{6}{|c|}{ Study } \\
\hline & & \multicolumn{2}{|c|}{ Semantic } & \multicolumn{2}{|c|}{ Physical } & \multicolumn{2}{|c|}{ Baseline } \\
\hline & & $\mathrm{E}$ & $S E$ & $\mathrm{E}$ & $S E$ & $\mathrm{E}$ & $S E$ \\
\hline \multirow[t]{2}{*}{ Full } & Recollection & 0.28 & 0.03 & 0.13 & 0.02 & & \\
\hline & Automatic & 0.31 & 0.03 & 0.41 & 0.02 & 0.32 & 0.02 \\
\hline \multirow[t]{2}{*}{ Reduced (42 subjects) } & Recollection & 0.25 & 0.03 & 0.12 & 0.03 & & \\
\hline & Automatic & 0.36 & 0.03 & 0.42 & 0.03 & 0.33 & 0.02 \\
\hline
\end{tabular}

Note-The upper part presents the estimates obtained from the full sample. The lower part presents the estimates obtained from the reduced sample (i.e., no zero at exclusion). 
whereas an advantage of physical over semantic processing occurred at automatic retrieval, thus suggesting some degree of dependency between recollection and automatic influences of memory. Estimates of the automatic influences of memory were significantly above chance in the physical condition, whereas, in the semantic condition, these were now not significantly different than baseline. It also appears that the removal of those subjects scoring zero at exclusion after semantic processing increased the estimates of automatic retrieval for this processing condition.

In the present experiment, 6 subjects did not complete any fragment in the exclusion semantic condition. This figure is larger than those observed in the previous two experiments ( 1 subject in the first experiment and 5 subjects in Experiment 2). A reduction in study time affecting intentional retrieval should have reduced the number of subjects capable of excluding all the items after semantic processing. We cannot provide a better reason for this result than to advocate individual differences in the memorial capabilities of the subjects across the three experiments.

\section{COMPARISON OF EXPERIMENTS 1, 2, AND 3}

It has been shown that increments in the available encoding time are positively related to explicit recollection when semantic processing is carried out on the target information, whereas no appreciable relationship seems present between processing time and explicit recollection at physical encoding (Craik \& Tulving, 1975). It is also known that study time does not influence performance in indirect/implicit memory tasks (see, e.g., Neill et al., 1990). Therefore, on the basis of these findings, it is possible to contrast the different predictions that can be made about the effect that a reduction in study time should have on the magnitude of the levels of processing effect for the estimates of recollection and automatic retrieval obtained with the PDP.

If recollection and automatic retrieval are independent, a reduction in study time from 1.5 to $1.0 \mathrm{sec}$ should reduce the advantage of semantic over physical processing on the estimates of recollection (i.e., $R_{\text {semantic }}-R_{\text {physical }}$ should show a steady decrease). The same prediction can be made if recollection and automatic retrieval are considered to be positively correlated.

Predictions differ, instead, in relation to the effect of semantic over physical processing when considering estimates of automatic retrieval. If recollection and automatic retrieval are independent, the advantage of physical over semantic processing observed on the estimates of automatic retrieval with $1.5 \mathrm{sec}$ at study should not be affected when study time is reduced to $1.0 \mathrm{sec}$ (i.e., $\mathrm{A}_{\text {se- }}$ mantic $-A_{\text {physical }}$ should stay constant). On the other hand, if the recollection and automatic influences of memory are positively related, a reduction in study time should reduce the advantage of physical over semantic process- ing at the level of the estimates of automatic retrieval (i.e., $A_{\text {semantic }}-A_{\text {physical }}$ should progressively tend toward zero). The reason is that fewer items are overall recollected with shorter presentation times; therefore, the items selection bias affecting the estimation of the automatic influences of memory should be reduced. As a consequence of this, the difference between the estimates of automatic retrieval under physical and semantic processing should progressively approach zero. This would be in line with failures to find levels of processing effects in indirect/implicit memory tasks (see, e.g., Graf \& Mandler, 1984; Hamman \& Squire, 1996; but see Brown \& Mitchell, 1994).

In order to test the above predictions, the effect of study time reduction on the $R_{\text {semantic }}-R_{\text {physical }}$ difference and on the $\mathrm{A}_{\text {semantic }}-\mathrm{A}_{\text {physical difference was assessed. Both }}$ analyses on the subjects estimates and on the estimates obtained after pooling all the observation across subjects and items are presented.

\section{Subject Analysis}

The difference between $R_{\text {semantic }}-R_{\text {physical }}$ and the difference between $A_{\text {semantic }}-A_{\text {physical }}$ was calculated for each subject in each of the three experiments (Figure 2A). A one-tailored linear trend analysis, using adjusted coefficients for unequal intervals, on the $R_{\text {semantic }}-R_{\text {physical }}$ dependent variable indicated that this difference decreased as a function of the reduction in the available study time $[t(141)=3.41, p<.01$, one-tail $]$. The $\mathrm{A}_{\text {semantic }}-\mathrm{A}_{\text {physical }}$ difference tended to become larger as a function of time reduction $[t(141)=1.57, p<.06$, one-tail]. When the same analysis was performed after removing the results from the subjects scoring zero in the exclusion semantic condition, similar results as those for the reduced sample were obtained (Figure $2 \mathrm{~B}$ ). The main difference was that the linear trend with the $A_{\text {semantic }}-A_{\text {physical }}$ dependent variable reached conventional significance. In fact, the linear trend on the $\mathrm{R}_{\text {semantic }}-\mathrm{R}_{\text {physical }}$ difference was significant $[t(129)=3.55, p<.01$, one-tail], indicating that a progressive reduction in the available study time reduces the advantage of semantic over physical processing on recollection. The linear trend on the $A_{\text {semantic }}-$ $A_{\text {physical }}$ difference was also significant $[t(129)=2.83$, $p<.01$, one-tail], indicating that a progressive reduction in the available study time reliably reduced the disadvantage of semantic over physical processing on automatic recollection.

Baseline levels were significantly different across the three experiments $\left[F(2,141)=4.15, M S_{\mathrm{e}}=0.013, p<\right.$ $.02]$. We do not have an explanation for this baseline discrepancy across the three experiments, given that they did not differ in the procedure used during the test phase. There is also no reason to think that small differences in the amount of the processing time available at study should have influenced baseline performance. However, it is important to consider that the previous analyses were carried out on difference scores between estimates and that these scores were not affected by baseline discrep- 

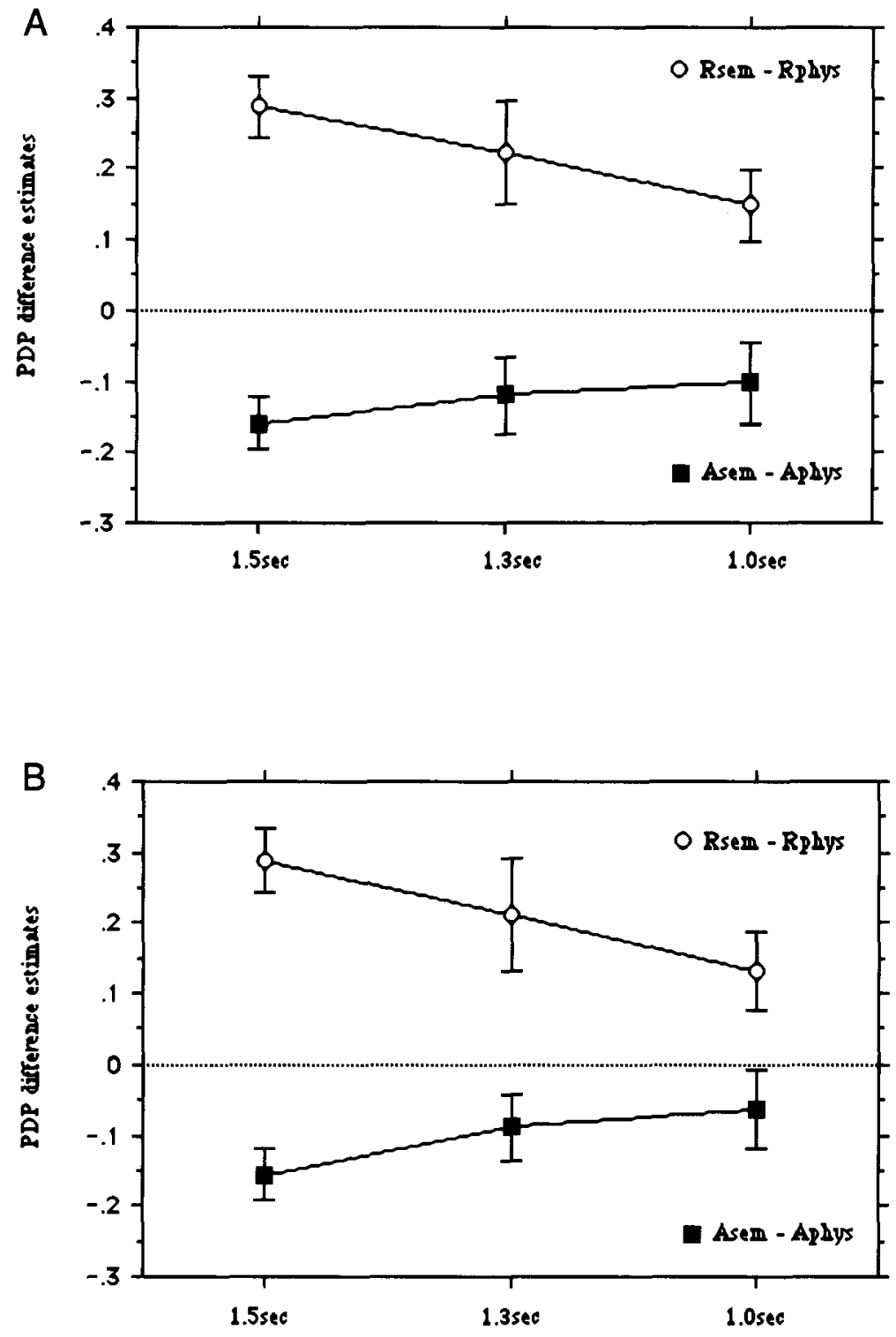

Figure 2. Graph combining the results of Experiments 1, 2, and 3. On the abscissa, the amount of time available at study in each of the three experiments is represented. The dependent variable is the difference in the PDP estimates between semantic and physical processing at the level of the recollection $\left(R_{\text {sem }}-\right.$ $R_{\text {phys }}$ ) and the automatic $\left(A_{\text {sem }}-A_{\text {phys }}\right.$ ) influences of memory. Figure $2 A$ represents the results obtained from full samples. Figure $2 B$ represents the results obtained from the no zeros at exclusion samples. Bars indicate $95 \%$ confidence intervals.

ancies. The estimates provided by the PDP equations can be unreliable if there is a significant discrepancy between baseline performances in inclusion and exclusion conditions. In none of the present experiments was this difference significant.

\section{Analyses on Pooled Data}

For each of the three experiments previously described, we calculated the differences between $R_{\text {semantic }}-R_{\text {physical }}$ and between $A_{\text {semantic }}-A_{\text {physical }}$, applying the PDP equa- tions to the pooled means obtained in the inclusion, exclusion, and baseline conditions, collapsing the data across all subjects and items. We also obtained, for inferential purposes, a $Z$ score on each of these differences in each experiment. Therefore, in order to assess the effect of a progressive lessening of the available study time on the above differences, we carried out a test on the significance of the linear trend contrasts, using these $Z$ scores (see Rosenthal \& Rosnow, 1991). For the benefit of the reader, we report each $Z$ score previously pre- 
sented to test each of the relevant difference between the estimates obtained after semantic and physical processing. In the case of the difference between $R_{\text {semantic }}-$ $\mathrm{R}_{\text {physical }}$, the obtained $Z$ scores for the 1.5-, 1.3-, and 1.0sec study time conditions were, respectively, 19.27, 16.56, and 12.62. A linear trend analysis showed that a steady reduction in the available study time reduced the advantage of semantic over physical processing at recollection $(Z=4.74, p<.01$, one-tail). The same analysis on the $A_{\text {semantic }}-A_{\text {physical }}$ difference showed that a lessening of the available study time reduced the advantage of physical over semantic processing at automatic retrieval $(Z=$ $3.53, p<.01$, one-tail; $Z$ scores for the 1.5-, 1.3-, and 1.0 -sec study time conditions were, respectively, -8.31 , -3.66 , and -3.02 ).

\section{DISCUSSION OF COMBINED EXPERIMENTS}

From the comparison of the recollection and automatic estimates obtained in Experiments 1,2, and 3, it appears that the advantage of semantic over physical processing at the level of the recollection estimates is reduced as a function of the lessening of the available study time from 1.5 to $1.0 \mathrm{sec}$. It also appears that the advantage of physical over semantic processing at the level of the estimates of automatic retrieval is reduced as a function of the study time reduction. This pattern of results is not compatible with the assumption of independence between recollection and automatic retrieval, whereas it can be accommodated if these forms of retrieval are considered to be correlated.

Overall, it appears that the difference between semantic and physical processing on automatic retrieval estimates tended toward nonsignificance when the advantage of semantic over physical processing at recollection was reduced. This suggests that it is possible to conceive of a situation in which a significant level of processing effect on recollection is coupled with a nonsignificant difference between the estimates of automatic retrieval after semantic and physical processing. This would produce a pattern of results apparently compatible with the relationship of independence between recollection and automatic retrieval. However, for the reasons outlined earlier, the very same pattern of results can be equally accommodated if these two forms of retrieval are considered to be positively correlated. There is, thus, the risk that any experimental result on cue completion tasks filtered with the PDP equations is uninterpretable.

Consider, for example, the following hypothetical scenario. It has been suggested, after a reexamination of the published results on the effect of LOP on implicit/indirect memory tasks, that semantic processing at study may have a genuinely positive effect, contrary to the more commonly held view that no such effect is evident, on perceptual priming, as compared with physical processing (see, e.g., Challis \& Brodbeck, 1992). Assuming that this is true and that recollection and automatic forms of retrieval are independent, the application of the PDP should lead, correctly, to the detection of an advantage of semantic over physical processing for both recollection and automatic forms of retrieval (see Figure 3A). However, if LOP has a truly positive effect on both the recollection and the automatic components and if these components are positively correlated, the application of the PDP equations may result in the misleading conclusion that there is no LOP effect at the level of the estimates of automatic retrieval, in which case the application of the PDP would erroneously support the mainstream view of no LOP effect on automatic retrieval. This result would occur because the large value of the automatic component for the few nonremembered items in the semantic condition would moderate the effect of the item selection bias induced by the low number of items not recognized in this processing condition (see Figure 3B).

These thought experiments indicate that, if the recollection and automatic influences of memory share a relationship of nonindependence, the application of the PDP cannot be used to reliably assess the influence of automatic and recollection retrieval modes. The PDP assumes independence between retrieval modes; thus, if these are not independent, the application of the PDP is bound to give misleading results. Overall, it appears that, if the relationship between retrieval modes is unknown, the application of the PDP to cue completion tasks is uninterpretable.

\section{GENERAL DISCUSSION}

To summarize, it appeared that the manipulation of LOP at study led to a larger effect of semantic processing over physical processing on the PDP estimates of the recollection influences of memory in all the three reported experiments. Contrary to what was expected from the assumption of independence between the recollection and automatic forms of retrieval, in each experiment we found a larger effect of physical over semantic processing on the estimates of automatic retrieval. This reverse LOP effect, coupled with the above finding of a standard LOP effect at the level of recollection, reflects a violation of the independence assumption between recollection and automatic influences of memory. Moreover, the finding in Experiment 1, in which the estimates of automatic retrieval were significantly below chance when target items were semantically processed at study, further supports the view that dissociations that do not make theoretical sense originate from a violation of the independence assumption.

Reverse effects that do not make theoretical sense, such as the one just described, were explained by Curran and Hintzman $(1995,1997)$ by considering the automatic and recollection influences of memory to be positively correlated across items within each subject. As described in the introduction, an item selection bias underlies the estimation process of automatic influences of memory. In fact, these estimates are based on nonrecollected items. Such item selection tends to be larger under those pro- 
A Not recollected Recollected

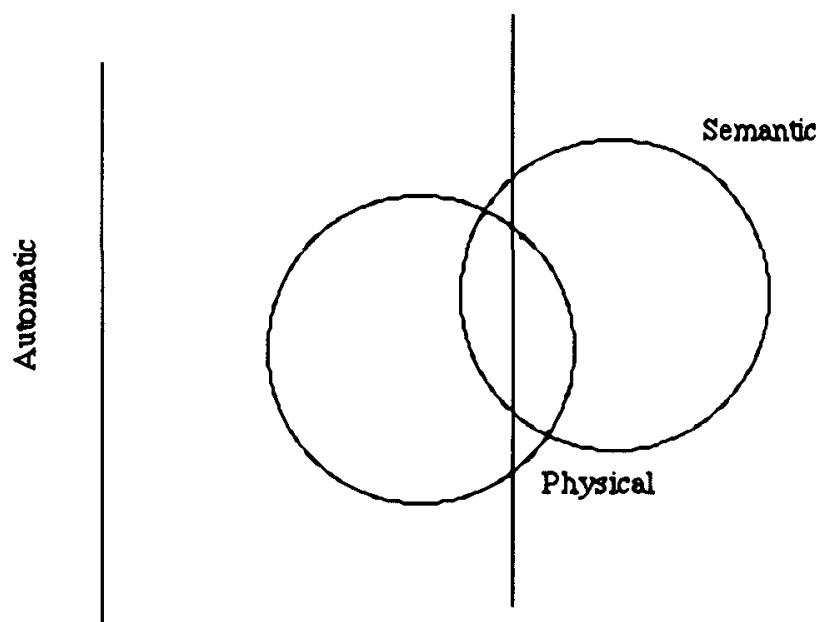

Recollection

B

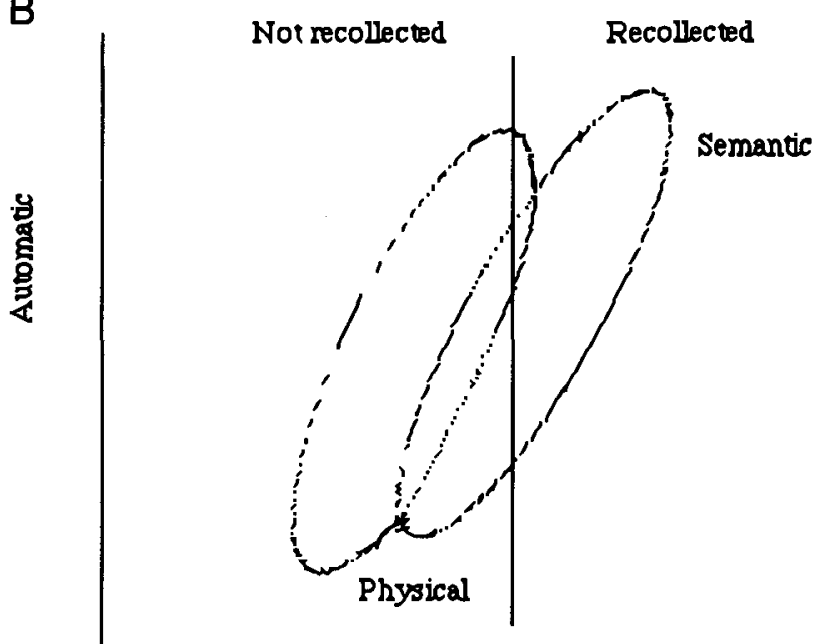

\section{Recollection}

Figure 3. Hypothetical representation of recollection (on the abscissa) and automatic (on the ordinate) influences of memory on each observation (i.e., item) when semantic processing is assumed to positively influence both recollection and automatic retrieval. In Figure 3A, these retrieval modes are represented as independent. In Figure 3B, they are represented as positively related. The vertical line in the middle of the picture indicates the criterion for recollection. Items to the left of the criterion are not recollected. Estimates of the automatic influences of memory for semantically and physically processed items are based on each of the subsets of items to the left of the criterion.

cessing conditions that lead to better recollection--that is, semantic processing. The consequence is an underestimation of the true influence of automatic retrieval that is more extreme for the level of the independent variable associated with greater recollection-that is, semantic processing. The outcome of this selection bias on the estimates of automatic retrieval is that the shallower the analysis at study, the larger the influence of automatic retrieval.
A comparison of the results of the three experiments was also undertaken in order to assess the effect of study time on the LOP effect for both recollection and the automatic components. According to the assumption of independence, a progressive reduction in the available study time from 1.5 to $1.0 \mathrm{sec}$ should have reduced the advantage of semantic over physical processing at the level of recollection, while leaving unchanged the advantage of physical over semantic processing on the estimates of 
automatic retrieval. Alternatively, if recollection and automatic components are considered to be positively correlated, the advantage of physical over semantic processing on the estimates of automatic retrieval was predicted to be reduced as a function of the lessening of the available study time. We found that the lessening of the study time affected the advantage of semantic over physical processing at recollection. We also found that the lessening of the study time reduced the advantage of physical over semantic processing on the estimates of automatic retrieval. This set of results is at variance with the assumption of independence, but it can be accommodated if the recollection and automatic retrieval modes are considered to be positively correlated.

In relation to this last point, we also showed, in a thought experiment, that, from the application of the PDP, it is possible to obtain meaningful but misleading results. Assuming that semantic processing was positively affecting both recollection and automatic retrieval and that the recollection and automatic components were positively correlated, we showed that it is possible to obtain incorrect results: No effect of LOP may be detected at the level of automatic estimates when, in fact, this effect is present. Overall, we think that the results obtained in this and in other studies (e.g., Curran \& Hintzman, 1995; Russo \& Andrade, 1995) cast doubt on the usefulness of the PDP for obtaining correct estimates of the automatic influences of memory, at least when applied to cue completion tasks.

It has been suggested that artifactual dissociations such as those observed in the present study may be produced if boundary conditions in the application of the PDP are violated (Jacoby, Begg, \& Toth, 1997; Toth, Reingold, \& Jacoby, 1995). These conditions mainly refer to the avoidance of zeros in the exclusion performance and to the fact that subjects use a direct retrieval strategy at test.

We dealt with the problem of zeros in the exclusion performance in two ways. First, we removed the subjects who scored zero at exclusion from the subject analysis on the estimates of the automatic and recollection components. ${ }^{3}$ Second, we pooled all the observations across items and subjects. With this last procedure, no zeros at exclusion were present. These approaches provided equivalent results, and they both indicated the presence of a crossed interaction between retrieval modes and LOP.

For a correct application of the PDP, it is prescribed, in both inclusion and exclusion tests, that subjects always try first to recollect a studied item with the help of a provided cue. This procedure should induce direct retrieval of the target information. It is important to note that target items can also be retrieved using a generate-recognize strategy. This means that the subjects in the exclusion condition, for example, try first to generate completions to fragments and then reject those recognized as old. This strategy is not compatible with the application of the PDP. In fact, it would induce a positive relationship between the automatic and recollection components. This occurs because recollection would depend on the successful output of automatic retrieval processes.
In order to induce a direct retrieval strategy, we used the type of instructions employed by Toth et al. (1994). It is important to note that these authors showed that there was no LOP effect, in a word stem completion task, on the estimates of automatic retrieval, whereas, in the present study, we repeatedly showed an advantage of physical over semantic processing on the estimates of automatic retrieval. Given that we obtained artifactual dissociations with a procedure that was prescribed to comply with the boundary conditions concerning retrieval strategies, these dissociations cannot be asserted to originate from a violation of this boundary condition. Interestingly, Toth et al. (1994) wrote that, in more recent experiments, they instructed their subjects in the exclusion test condition to "use the stem as a cue to recall one of the words from the first part of the experiment; however, you should complete the stem with a different word--that is, a word that was not presented in the first part of the experiment" (p. 303). These instructions were probably intended to more precisely focus the subjects on a direct retrieval mode. It is relevant to note that, using instructions equivalent to these, Richardson-Klavehn, Gardiner, and Ramponi (1996) showed, in a word stem completion task, an advantage of physical over semantic processing on the estimates of the automatic influences of memory. An analysis of the reaction times of the subjects' responses in this study also suggested that the subjects in both the inclusion and the exclusion conditions were mainly trying first to recollect target items. Overall, it seems that, with different instructions that do not violate the boundary condition about retrieval strategies, it is possible to obtain theoretically nonmeaningful dissociations.

As was said earlier, if subjects adopt a generaterecognize retrieval strategy, the PDP equations cannot be successfully applied. Fundamentally, the PDP relies on the fact that subjects follow, in the inclusion and exclusion tasks, a direct retrieval strategy. If, instead of a direct retrieval strategy, subjects adopt a generate-recognize strategy, a positive relationship between automatic and recollection influences of memory is bound to occur, because recollection occurs when subjects recognize items successfully generated. It may be difficult for a subject to uniformly follow a direct retrieval strategy in cue completion tasks, despite instructions stressing to various degrees compliance with this retrieval strategy. One possible reason is that automatic generation is a faster process than is recollection (see, e.g., Toth, 1996); thus, it is likely that, despite direct retrieval instructions, subjects often generate items first and then operate a recognition check on the outcome of the automatic generation. Consider also the situation in which, at exclusion, subjects fail to recollect a target but this is then produced automatically. Under these circumstances, it is plausible to suppose that subjects may then operate a recognition check on this generated item. If this is successful, the target cue will not be completed at exclusion. Alternatively, a subject may become aware of having encountered a generated item at study despite intentional recol- 
lection having failed, and thus the subject will not complete the target cue at exclusion (on this issue, see Richardson-Klavehn, Gardiner, \& Java, 1994). The end result is that subjects' performance in cue completion tasks may reflect a mixture of strategies, despite the emphasis given in the test instructions to operate according to a direct retrieval mode. The consequence of this is that the possibility to apply the PDP in these tasks is seriously compromised.

That memory tasks are not process pure seems a position potentially having not many opponents; nevertheless, to find a method to tease apart these components is not an easy enterprise. As theoretical extrapolations from indirect memory tasks may suffer from the fact that these tasks do not measure unique processes, theorizing on process dissociations based on the PDP may induce erroneous conclusions because of violations of independence. We do not feel, however, in a position to generalize this conclusion to paradigms other than cue completion tasks. The status of the assumptions underlying the PDP in other paradigms needs to be considered separately from the present findings.

\section{REFERENCES}

Basden, B. H., Basden, D. R., \& GaRgano, G. J. (1993). Directed forgetting in implicit and explicit memory tests: A comparison of methods. Journal of Experimental Psychology: Learning, Memory, \& Cognition, 19, 603-616.

Blaxton, T. A. (1989). Investigating dissociations among memory measures: Support for a transfer appropriate processing framework. Journal of Experimental Psychology: Learning, Memory, \& Cognition, 15, 657-668.

Brown, A. S., \& Mitchell, D. B. (1994). A reevaluation of semantic versus nonsemantic processing in implicit memory. Memory \& Cognition, 22, 533-541.

Buchner, A., Erdfelder, E., \& VAtTerodt-Plünnecke, B. (1995). Toward unbiased measurement of conscious and unconscious memory processes within the process dissociation framework. Journal of Experimental Psychology: General, 124, 137-160.

CHALLIS, B. H., \& BRODBECK, D. R. (1992). Level of processing affects priming in word fragment completion. Journal of Experimental Psychology: Learning, Memory, \& Cognition, 18, 595-607.

Craik, F. I. M., \& Tulving, E. (1975). Depth of processing and the retention of words in episodic memory. Journal of Experimental Psychology: General, 104, 268-294.

Curran, T., \& Hintzman, D. L. (1995). Violations of the independence assumption in process dissociation. Journal of Experimental Psychology: Learning, Memory, \& Cognition, 21, 531-547.

Curran, T., \& Hintzman, D. L. (1997). Consequences and causes of correlations in process dissociation. Journal of Experimental Psychology: Learning, Memory, \& Cognition, 23, 465-504.

GRAF, P., \& MANDLER, G. (1984). Activation makes words more accessible but not necessarily more retrievable. Journal of Verbal Learning \& Verbal Behavior, 23, 553-568.

Hamman, S. B., \& SquirE, L. R. (1996). Levels-of-processing effects in word-completion priming: A neuropsychological study. Journal of $E x$ perimental Psychology: Learning, Memory, \& Cognition, 22, 933-947.

JACOBY, L. L. (1991). A process dissociation framework: Separating automatic from recollection uses of memory. Journal of Memory \& Language, 30, 513-541.

JACOBY, L. L., BEGG, I. M., \& ToTH, J. P. (1997). In defense of functional independence: Violations of assumptions underlying the process-dissociation procedure? Journal of Experimental Psychology: Learning, Memory, \& Cognition, 23, 484-495.
JACOBY, L. L., TOTH, J. P., \& YonelinaS, A. P. (1993). Unconscious influences of memory: Attention, awareness, and control. Journal of Experimental Psychology: General, 122, 139-154.

Mulligan, N. W., \& HarTman, M. (1996). Divided attention and indirect memory tests. Memory \& Cognition, 24, 453-465.

Neill, T. W., Beck, J. L., Bottalico, K. S., \& Molloy, R. D. (1990). Effects of recollection versus incidental learning on explicit and implicit tests of memory. Journal of Experimental Psychology: Learning, Memory, \& Cognition, 16, 457-463.

Parkin, A. J., ReID, T. K., \& Russo, R. (1990). On the differential nature of implicit and explicit memory. Memory \& Cognition, 18, 507-514.

Richardson-KLAVEHN, A., Gardiner, J. M., \& JaVA, R. I. (1994). Involuntary conscious memory and the method of opposition. Memory, 2, 1-29.

Richardson-Klayehn, A., Gardiner, J. M., \& Ramponi, C. (1996, November). Does depth of processing influence involuntary retrieval in stem completion? Paper presented at the 37th Annual Meeting of the Psychonomic Society, Chicago.

ROEDIGER, H. L., III, \& MCDERMOTT, K. B. (1993). Implicit memory in normal human subjects. In H. Spinnler \& F. Boller (Eds.), Handbook of Neuropsychology (Vol. 8, pp. 63-131). Amsterdam: Elsevier

ROSENTHAL, R., \& RosNow, R. L. (1991). Essentials of behavioral research: Methods and data analysis. New York: McGraw-Hill.

Russo, R., \& ANDRADE, J. (1995). The directed forgetting effect in word fragment completion: An application of the process dissociation procedure. Quarterly Journal of Experimental Psychology, 48A, 405423.

Russo, R., \& PARKIN, A. J. (1993). Age differences in implicit memory: More apparent than real. Memory \& Cognition, 21, 73-80.

SChacter, D. L., Chiu, C.-Y., \& OChesner, K. N. (1993). Implicit memory: A selective review. Annual Review of Neuroscience, 16, 159-182.

SRINIVAS, K., \& RoEdiger, H. L., III (1990). Testing the nature of two implicit tests: Dissociations between conceptually-driven and datadriven processes. Journal of Memory \& Language, 28, 389-412.

Tотн, J. P. (1996). Conceptual automaticity in recognition memory: Levels-of-processing effects on familiarity. Canadian Journal of Experimental Psychology, 50, 123-138.

TorH, J. P., ReINGOLD, E. M., \& JACOBY, L. L. (1994). Towards a redefinition of implicit memory: Process dissociations following elaborative processing and self-generation. Journal of Experimental Psychology: Learning, Memory, \& Cognition. 20, 290-303.

Toth, J. P., Reingold, E. M., \& JACOBY, L. L. (1995). A response to Graf and Komatsu's critique of the process dissociation procedure: When is caution necessary? European Journal of Cognitive Psychology, 7, 113-130.

\section{NOTES}

1. A third analyses could be performed on the estimates of $R$ and $A$ for each item. However, in the present case, this does not appear to be feasible. Only a maximum of eight observations per condition can be used to calculate estimates of $R$ and $A$. This means that, for a large number of items, zero scores will occur in the inclusion and exclusion conditions. Under these circumstances, unreliable values of $R$ and $A$ would be estimated.

2. Recently, Buchner, Erdfelder, and Vatterodt-Plünnecke (1995) suggested a set of revised PDP equations to take into account bias in the measurement of the recollection and automatic influences of memory. Their method allows the calculation of estimates of memory components that are directly purified from baseline performance. This purification is accomplished for both the recollection and the automatic memory influences. This method was originally applied to recognition memory in which variables were manipulated between subjects, but the use of the revised formulas to calculate components estimates can easily be extended to completion tasks in within-subjects studies. It is interesting to note that the application of these variants of the PDP equations to our subjects data led to results comparable with those obtained with the original equations, thus suggesting that the results we obtained still occur when a different weight to baseline performance is given by 
the PDP equations. The similarity in the pattern of the obtained results using the original PDP formulas and their variants occurred also in Experiments 2 and 3 .

3. A reviewer suggested that near floor performance can distort PDP estimates. Assuming that this is true, it is, however, unclear what could be the criterion for deciding that a performance is near floor. Assuming that a near floor effect can reasonably be motivated to correspond to an exclusion performance of one item, a reanalysis of the data can be performed to ascertain the effect of LOP on automatic and recollection estimates. The number of subjects who completed at least two items in the exclusion semantic condition were 31,38, and 37 in Experiments 1, 2, and 3, respectively. Equivalent analyses to those performed on the no zeros at exclusion samples gave almost equivalent results. The only differences that appeared between the no zeros and the no zeros and no ones analyses were the following. When study time was 1.3 and $1.0 \mathrm{sec}$
(Experiments 2 and 3), estimates of automatic retrieval were significantly larger than baseline, and, in Experiment 3, the advantage of physical over semantic analysis was nonsignificant.

This last result suggests that, if a no near floor policy is enforced, it is possible to obtain automatic estimates from the subject analysis that apparently support the relationship of independence between the recollection and the automatic influences of memory. It is nevertheless important that this result be evaluated within the context of all the experiments reported in the present study. If this is done, it appears that in only one experiment out of three, we obtained a result that seemed to support a relationship of independence between automatic and recollection retrieval modes. However, the results from all experiments cannot be accommodated under the assumption of independence. These can be accommodated if the recollection and automatic influences of memory are considered to be positively correlated.

\section{Words, Fragments, and Their Assigned Subset Used in the Experiments}

\begin{tabular}{|c|c|c|c|c|c|}
\hline accordion & ${ }_{-} \operatorname{ccor} \mathrm{r}_{-} \mathrm{n}$ & al & parasite & $p_{--}$asi_e & a2 \\
\hline $\begin{array}{l}\text { carrot } \\
\text { champagne }\end{array}$ & 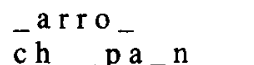 & al & punishment & $\mathrm{p}_{-} \mathrm{ni}-\mathrm{me}_{-} \mathrm{t}$ & a2 \\
\hline $\begin{array}{l}\text { champagne } \\
\text { chimpanzee }\end{array}$ & $\begin{array}{l}c h_{-} p^{a}{ }_{-} n_{-} \\
c p_{-} p_{-} e^{-}\end{array}$ & a1 & salesman & $-\mathrm{al}_{--} \mathrm{m}_{-} \mathrm{n}$ & a2 \\
\hline $\begin{array}{l}\text { chimpanzee } \\
\text { concrete }\end{array}$ & $c_{-i m p_{-} n_{-}}^{c_{-} e_{-}}$ & al & scissors & ${ }_{-}$is s $s_{-} \mathbf{s}$ & a2 \\
\hline $\begin{array}{l}\text { concrete } \\
\text { dolphin }\end{array}$ & 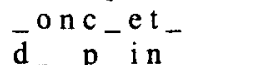 & al & snuggle & $\mathrm{s}_{-} \mathrm{u}_{-} \mathrm{g}_{-} \mathrm{e}$ & a2 \\
\hline $\begin{array}{l}\text { dolphin } \\
\text { eagle }\end{array}$ & $e_{-a^{-}} p_{e^{i n}}$ & al & trumpet & - rump $p_{--}$ & a2 \\
\hline $\begin{array}{l}\text { eagle } \\
\text { fishing }\end{array}$ & 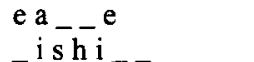 & al & turtle & $-u r t \_e$ & a2 \\
\hline $\begin{array}{l}\text { fishing } \\
\text { guitar }\end{array}$ & $\begin{array}{l}- \text { ishi } \\
\text { uita }\end{array}$ & al & valium & $-\mathrm{ali}_{--}$ & a2 \\
\hline $\begin{array}{l}\text { guitar } \\
\text { hemlock }\end{array}$ & 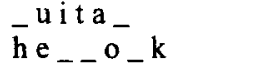 & $\begin{array}{l}\text { al } \\
\text { al }\end{array}$ & abdomen & ${ }_{-} b d_{-} m e_{-}$ & b1 \\
\hline hydrogen & $h_{-} \bar{d} r_{--} e n$ & al & banana & anan & b1 \\
\hline jukebox & $\mathrm{j}_{-}^{-} \mathrm{eb} \mathrm{o}_{-}$ & al & bashful & $\bar{b}_{-} s_{-}-\bar{u} \mathbf{l}$ & bl \\
\hline lemon & $1_{-} \mathrm{mo}$ & al & butterfly & - utt ${ }_{-} r_{-} \mathrm{l}_{-}$ & bl \\
\hline lobster & $-0 b s_{-} e_{-}$ & al & camera & $-\mathrm{a} \mathrm{m} \mathrm{e}_{--}$ & bl \\
\hline lucifer & $1_{-} \mathrm{ci} \mathrm{i}_{-} \mathrm{e}_{-}$ & al & cannon & ca $a_{--}$on & bl \\
\hline migraine & $m_{-} g_{-} a_{-}$ & al & cinder & $-i n d e_{-}$ & bl \\
\hline mountain & $\mathrm{mo}_{--} \mathrm{tai}$ & al & $\begin{array}{l}\text { computer } \\
\text { crown }\end{array}$ & & bl \\
\hline nausea & $\mathrm{na}_{-} \mathrm{se}_{-}$ & al & $\begin{array}{l}\text { crown } \\
\text { enunciate }\end{array}$ & $e_{-}^{c} \mathrm{ow}_{-} \mathrm{i}_{--}$ & $\begin{array}{l}\text { bl } \\
\text { b1 }\end{array}$ \\
\hline $\begin{array}{l}\text { perfume } \\
\text { plague }\end{array}$ & $\begin{array}{l}-e_{-} r_{-} e_{-} \\
l_{1} a_{-} e_{e}\end{array}$ & $\begin{array}{l}\text { al } \\
\text { al }\end{array}$ & envelope & en_el & bl \\
\hline $\begin{array}{l}\text { plague } \\
\text { quarantine }\end{array}$ & -aran_in & al & freckle & $f_{-} e c_{-} I_{-}$ & bi \\
\hline radiation & $-a d_{-} a_{-} i o n$ & al & glaucoma & $-1 \mathrm{a} u_{-} o_{-} a$ & bl \\
\hline rattlesnake & $r_{-} t_{-} e s_{-} a_{-} e$ & al & impotence & $\mathrm{im}_{-} \mathrm{ot} \mathrm{t}_{-} \mathrm{ce}$ & b1 \\
\hline rebuttal & $\mathrm{re} \mathrm{e}_{-} \mathrm{u}_{--} \mathrm{al}$ & al & jungle & $-\mathrm{un}_{-} \mathrm{le}$ & bl \\
\hline torso & - ors & a1 & $\begin{array}{l}\text { legislature } \\
\text { martini }\end{array}$ & $\mathrm{le}_{-}$is $l_{-} \mathrm{tu} \mathrm{u}_{-} \mathrm{e}$ & bl \\
\hline zeppelin & ${ }_{-}^{e} p_{-} e l i{ }_{-}$ & al & needle & $\begin{array}{l}\mathrm{ma}_{-} \mathrm{ti}_{-}- \\
-\mathrm{e} \mathrm{d}_{-} \mathrm{e}\end{array}$ & $\begin{array}{l}\text { bl } \\
\text { b1 }\end{array}$ \\
\hline architect & $-r c_{-} i_{-} e_{-} t$ & $\mathrm{a} 2$ & peanut & $\overline{\mathrm{p}}_{--} \mathrm{n} \overline{\mathrm{u}}_{-}$ & bl \\
\hline ashtray & $a_{-} h t_{-} a_{-}$ & a2 & pencil & $e_{-} \mathrm{ci}_{-}$ & bl \\
\hline balloon & _all_on & a2 & pitcher & $-i_{-}$cher & b1 \\
\hline barrel & $\mathrm{b} \mathrm{a}_{--} \mathrm{el}$ & a2 & poverty & ${ }_{-} o v_{-} r_{-} y$ & bl \\
\hline bicycle & $-i c_{-} c_{-} e$ & a2 & rabbit & $-a b_{-} i_{-}$ & bl \\
\hline capillary & $a_{-} a_{-} i l l_{-} r_{-}$ & a2 & rubella & $\mathrm{r}_{-}-\mathrm{ell} \mathrm{l}_{-}$ & bl \\
\hline castle & $c_{-} s_{-} l e$ & a2 & sequoia & $\mathrm{s}_{-\ldots} \mathrm{o}$ i a & b1 \\
\hline christening & $c_{-} \mathrm{ri}_{-}$enin & a2 & tragedy & ${ }_{-} \mathrm{rage}_{-}$ & bl \\
\hline cloud & $c_{-}-o u_{-}$ & a2 & arrow & $\mathrm{ar}_{-} \mathrm{o}_{-}$ & b2 \\
\hline $\begin{array}{l}\text { cocaine } \\
\text { elephant }\end{array}$ & $\bar{e}^{0 c a} \bar{b}^{-e}$ & a2 & button & $b_{-} \bar{t}_{-} \bar{o}_{-}$ & b2 \\
\hline $\begin{array}{l}\text { elephant } \\
\text { flower }\end{array}$ & $\begin{array}{l}\mathrm{e}_{-} \mathrm{e}_{-} \mathrm{ha}_{-}-\mathrm{we}_{-} \mathrm{e}_{-} \\
-10\end{array}$ & $\begin{array}{l}\mathrm{a} 2 \\
\mathrm{a} 2\end{array}$ & bottle & ${ }_{-} o_{-} \mathrm{tl}_{-}$ & b2 \\
\hline grapes & $\bar{g}_{--} \mathrm{pe}_{-}$ & $\mathrm{a} 2$ & caricature & $\mathrm{ca}_{-} \mathrm{ica} \mathrm{a}_{-} \mathrm{u}_{--}$ & b2 \\
\hline ladder & $1 a_{--} e_{-}$ & a2 & coffee & $c_{-} \mathrm{fe}_{-}$ & b2 \\
\hline limerick & $1 i_{-}^{-e_{-}} \overline{i c_{-}}$ & a2 & cologne & $\mathrm{co}_{-} \mathrm{og}_{-} \mathrm{e}$ & b2 \\
\hline margarita & $\mathrm{m}_{-} \mathrm{r}_{-} \mathrm{a}_{-} \mathrm{i}_{-} \mathrm{a}$ & a2 & comma & $-0 \mathrm{~m}_{-}-$ & b2 \\
\hline midget & $\mathrm{m}_{-} \mathrm{d}_{-} \mathrm{e}_{-}$ & a2 & escalator & $\mathrm{e}_{-} \mathrm{c}_{-} \mathrm{la}_{-} \mathrm{or}$ & b2 \\
\hline mushroom & $-u_{-} \mathrm{ro}_{-} \mathrm{m}$ & a2 & gestation & $\mathrm{ge}_{-} \mathrm{ta}_{-}$ion & b2 \\
\hline
\end{tabular}


APPENDIX (Continued)

\begin{tabular}{|c|c|c|c|c|c|}
\hline kangaroo & ${ }_{-} \mathrm{anga} \mathrm{a}_{-}$ & b2 & saliva & $\mathrm{s}_{-} \mathrm{li}_{-} \mathrm{a}$ & $\mathrm{cl}$ \\
\hline liberty & $\bar{l}_{-} \mathrm{ert}_{-}$ & $\mathrm{b} 2$ & stalagmite & $-\bar{t}$ a l a ${ }_{-} i_{-} e$ & $\mathrm{cl}$ \\
\hline maggot & $-\mathrm{ggo}_{-}$ & b2 & tornado & tor__ $\mathrm{d}_{-}$ & $\mathrm{cl}$ \\
\hline metropolis & $\mathrm{me}_{-} \mathrm{r}_{-} \mathrm{oli}_{-}$ & b2 & treason & $\mathrm{t}_{-} \mathrm{e}_{-} \mathrm{s}_{-} \mathrm{n}$ & $\mathrm{c} 1$ \\
\hline monarch & ${ }_{-} \mathrm{ona} \mathrm{a}_{-} \mathrm{c}_{-}$ & b2 & umbrella & ${ }_{-} \mathrm{m}_{-} \mathrm{rel} \mathrm{l}_{-} \mathrm{a}$ & $\mathrm{c} 1$ \\
\hline monologue & $\overline{\mathrm{m}}_{-} \mathrm{o} \mathrm{lo}_{-} \mathrm{ue}$ & $\mathrm{b} 2$ & vanilla & $\bar{v}_{-}+111_{-}$ & $\mathrm{cl}$ \\
\hline nurse & $\mathrm{nu}_{-} \mathrm{e}$ & b2 & velocity & $\bar{e}_{-} o c_{-} t_{-}$ & $\mathrm{cl}$ \\
\hline paratrooper & pa_a t $r_{-}$per & b2 & whistle & ${ }_{-} h_{-} s_{-} l e$ & $\mathrm{cl}$ \\
\hline proverb & $\mathrm{p}_{-} \mathrm{o}_{-}$e $\mathrm{r}_{-}$ & b2 & ambulance & $a_{-} b_{-} l_{a} c_{-}$ & c2 \\
\hline $\begin{array}{l}\text { purple } \\
\text { sailboat }\end{array}$ & $-\mathrm{ur}_{\mathrm{ai}}^{\mathrm{u}}-{ }^{1}-\overline{\mathrm{o}}$ a & $\begin{array}{l}b 2 \\
b 2\end{array}$ & cathode & $c_{-} t_{--}$ & $\mathrm{c} 2$ \\
\hline sanitary & sa $a_{-}{ }_{i t a}$ & $\begin{array}{l}\text { D2 } \\
\text { b2 }\end{array}$ & cheetah & $-\bar{h} e_{-} \mathrm{a}$ & c2 \\
\hline socialism & $\mathrm{s}_{-} \mathrm{ia}_{-} \mathrm{is}$ & b2 & church & $\mathrm{c}_{-} \mathrm{urc}$ & $\mathrm{c} 2$ \\
\hline superstition & $\mathrm{s}_{-}$ers $\mathrm{i}_{-} \mathrm{io}$ & b2 & clarinet & $\mathrm{cl}_{-}$in $\mathrm{e}_{-}$ & c2 \\
\hline tomato & to $o_{-} a_{-} o_{0}$ & b2 & daisy & $\mathrm{da}_{-} \mathrm{s}_{-}$ & c2 \\
\hline vacuum & $-\mathrm{acu}-\mathrm{m}$ & b2 & fireplace & $-\mathrm{ire}{ }_{-}{ }_{-} \mathrm{ce}$ & c2 \\
\hline agnostic & $a \quad n \quad t i$ & $\mathrm{cl}$ & $\begin{array}{l}\text { fluoride } \\
\text { igloo }\end{array}$ & $\begin{array}{l}f_{-} \mathrm{uo}_{-} \mathrm{i}_{-} \\
\mathrm{i} 10^{-}\end{array}$ & $\begin{array}{l}\mathrm{c} 2 \\
\mathrm{c} 2\end{array}$ \\
\hline anchor & $\bar{n} c_{-} o_{-}$ & $\mathrm{cl}$ & jeopardy & eo_ard & c2 \\
\hline attic & $-i c$ & $\mathrm{cl}$ & justice & usti_e & $\mathrm{c} 2$ \\
\hline basketball & b a s $\ldots \ldots$ a 11 & $\mathrm{cl}$ & marble & arbl_ & $\mathrm{c} 2$ \\
\hline checkers & $c_{-} c_{-} e_{-} s$ & cl & merchant & erc_ant & $\mathrm{c} 2$ \\
\hline colleague & $-\bar{o}_{-} 11 \mathrm{e}_{-}$ & $\mathrm{cl}$ & monastery & $\bar{m}_{-}-\overline{a s}_{-} \mathrm{ry}$ & c2 \\
\hline constituency & $\bar{c}_{-} n s_{-} i_{-} u_{-} n_{-} y$ & $\mathrm{cl}$ & mongoose & - on_oo_e & $\mathrm{c} 2$ \\
\hline corporal & $\mathrm{co}_{-} \mathrm{ora}_{-}$ & cl & monogram & $\mathrm{mo}_{-} \mathrm{gr}_{--}$ & $\mathrm{c} 2$ \\
\hline diamond & $\mathrm{d}_{-} \mathrm{a}_{-} \mathrm{o}_{-} \mathrm{d}$ & cl & nickel & $\mathrm{ni}_{-} \mathrm{e}_{-}$ & $\mathrm{c} 2$ \\
\hline exaggeration & $\overrightarrow{\mathrm{ex}} \overline{-}_{-} \overrightarrow{\mathrm{era}} \mathrm{i} \mathrm{o}_{-}$ & cl & octopus & ${ }_{-} \mathrm{cto} \overline{\mathrm{u}}_{-}$ & $\mathrm{c} 2$ \\
\hline folder & oold & c1 & peppermint & e p_er in & $\mathrm{c} 2$ \\
\hline fusion & $-u s i_{-}$ & cl & prison & $\overline{\mathrm{p}} \mathrm{r}_{-} \mathrm{s} \mathrm{o}_{-}$ & $\mathrm{c} 2$ \\
\hline giraffe & $-\operatorname{ira}{ }_{-} e$ & c1 & pumpkin & $-u m_{-}$in & $\mathrm{c} 2$ \\
\hline gymnastics & ${ }_{-} m n_{-} s t i_{-} s$ & cl & recluse & $\bar{r}_{-} \mathrm{cl}_{-} \mathrm{se}$ & $\mathrm{c} 2$ \\
\hline innocent & $n_{-}$ce $n_{-}$ & $\mathrm{cl}$ & refrain & $r \bar{e}_{-} \mathrm{rai}$ & $\mathrm{c} 2$ \\
\hline magician & ${ }_{-} \bar{g}_{-} \mathrm{ci}$ & c1 & thumb & $t_{-} \bar{u}_{-} b$ & $\mathrm{c} 2$ \\
\hline python & $\bar{p}_{-} t_{-} o_{-}$ & cl & toaster & to & $\mathrm{c} 2$ \\
\hline reprimand & $\mathrm{re}_{-} \mathrm{ri}_{-} \mathrm{an}_{-}$ & $\mathrm{cl}$ & window & - ind o & $\mathrm{c} 2$ \\
\hline
\end{tabular}

(Manuscript received October 20, 1995;

revision accepted for publication May 13, 1997.) 